\title{
The Role of Outgroups in Constructing a Shared Identity: A Longitudinal Study of a Subsidiary Merger in Mexico
}

\author{
Anna Lupina-Wegener • Susan C. Schneider • \\ Rolf van Dick
}

Received: 13 October 2013/Revised: 25 January 2015/Accepted: 4 February 2015/

Published online: 27 March 2015

(C) Springer-Verlag Berlin Heidelberg 2015

\begin{abstract}
Both scholars and practitioners agree that constructing a shared organizational identity is necessary for successful outcomes in mergers and acquisitions. Yet the process of constructing shared identity is not an easy path. We report findings of a longitudinal in-depth case study of merging Mexican subsidiaries-part of two European Multinational Corporations. The study took advantage of a rare opportunity that includes prior knowledge of the merger and permission to follow-up until post-merger integration concluded. Particularly, in the studied case, status differences between premerger organizations were removed, external boundaries were reinforced and new outgroups emerged, namely the Head Offices and Latin American divisions. Our study contributes to the M\&A literature, to the stakeholder approach to organizational identity and to identity construction in nested organizations. We shed light on how intergroup dynamics change over time during interactions between internal and external stakeholders, and whose status changes in the post-merger organization. Based on these findings, we argue that considering both intragroup and intergroup dynamics can refine the concept of shared organizational identity. Intragroup dynamics refers to employees of the post-merger organization, and intergroup dynamics refers to outgroup-outside the post-merger organization. We coin a concept of an optimal shared identity, defined
\end{abstract}

The study was financed by Fonds d'appui à l'internationalisation received by the first author, University of Geneva, Switzerland.

\section{A. Łupina-Wegener ( $\square)$}

School of Business and Engineering Vaud, University of Applied Sciences and Arts Western Switzerland, Yverdon-les-Bains, Switzerland

e-mail: anna.lupina-wegener@heig-vd.ch

\section{S. C. Schneider}

Professor Emeritus, University Geneva, Geneva, Switzerland

R. van Dick

Goethe University, Frankfurt, Germany

e-mail:van.dick@psych.uni-frankfurt.de 
as the members' shared belonging to the post-merger organization and to the Multinational Corporation (on the global or regional level) in the face of salient outgroups.

Keywords Identity conflict - Identity construction process - Mergers · Nested organizations · Longitudinal study

\section{Introduction}

The creation of a new organizational identity is crucial to the success of major strategic change initiatives. Prior research has demonstrated that organizational identity is related to positive outcomes such as the intention to remain in the organization, job satisfaction, work motivation, and cooperative behavior (Riketta 2005; Rousseau 1998). Much of the prior research is based on social identity theory (Tajfel and Turner 1986), which posits a duality between an individual's personal and social identities. Membership in groups, i.e. social identity, can contribute to an individual's self-esteem and wellbeing. However, it can also be a source of conflict when group members aim to positively differentiate their ingroup from relevant outgroups. This is particularly apparent in mergers and acquisitions (M\&As) wherein employees often face difficulties moving away from pre-merger identity and embracing a new, shared post-merger identity. We define organizational identity as what is considered by organizational members to be the "central, distinctive and enduring characteristic of an organization"(Albert and Whetten 1985). Organizational identification refers to as the individual's perception of the sharedness of this organizational identity as put forth by Ashforth and Mael (1989). Organizational identification helps an individual to define him- or herself by sharing aspects of the organization's identity with others. However, the organization, as a whole or in parts (such as subsidiaries that are studied here), does not necessarily have a monolithic identity (Scott and Lane 2000).

Some M\&A scholars argue that identity conflict impedes the construction of a shared identity and thus should be avoided (Buono, Bowditch and Lewis 1985; Marks and Mirvis 2001; Meyer and Altenborg 2007; Nahavandi and Malekzadeh 1988). More recent research reveals that conflict between identities of pre-merger groups might be a natural stage in developing a shared, post-merger identity (Fiol, Pratt and O'Connor 2009). Specifically, employees' attachment to their pre-merger identity may dissipate over time (Gleibs et al. 2008). Thus, it is important for leaders to lay a roadmap of the organization's future identity, to direct and facilitate employees' attachment to the post-merger identity (Chreim 2007; Clark et al. 2010; Ullrich et al. 2005). Despite these important insights, the majority of M\&A research is chiefly static with only few exceptions (Raukko 2009).

In this study, we will focus on the following research questions:

1. How do subsidiary intergroup dynamics shape the construction of a shared organizational identity?

2. Which issues contribute to these intergroup dynamics in subsidiary M\&As? 
The longitudinal study presented in this paper will address these questions. To this end, we have conducted a qualitative in-depth case study on a merger of Mexican subsidiaries of two European Multinational Corporations (MNCs). Alpha-Corp, ${ }^{1}$ a large European multidivisional Multinational Corporation (MNC) merged with Beta-Pharma, a specialized, research oriented company in the same European country. We began the investigation with pilot interviews 1 month before post-merger integration began (time 0), after 7 months (time 1; T1) and 3 years later (time 2; T2). Consequently, we used the grounded theory approach to process theory building (Corbin and Strauss 2008) in longitudinal research (Pettigrew 1990; Vincze 2013) to identify issues in intergroup dynamics and the consequent implications for constructing a shared organizational identity. We address the process of shared identity construction (theoretical domain) in M\&As (problem domain).

The findings provide insights into how intergroup dynamics in the post-merger subsidiary were influenced by the Head Office. In the early phase of the merger, the Global Head Office removed status asymmetries of the merging subsidiaries. Later on, it reinforced external boundaries of the post-merger subsidiary to which we will refer to as a "post-merger organization" in the rest of the text. As a result, the Head Office become a new outgroup and two pre-merger groups in Mexico were integrated. However, optimal shared post-merger identity has not yet developed. Specifically, we theorize on the concept of shared identity in M\&As. We argue it should account for both intragroup dynamics ("us", the post-merger organization) and intergroup dynamics (relation to "them", outgroup(s) outside the post-merger organization). We introduce the concept of optimal shared identity, defined as the employees' shared belonging to the post-merger organization and to the MNC (on the global or regional level) in the face of salient outgroups.

Our paper is structured as follows. We will begin by reviewing the social identity approach to M\&As. Next, we present the results of the longitudinal in-depth case study on a merger within the Mexican subsidiaries of two European MNCs. We conducted this research in a rare situation: we had prior knowledge of the merger, and senior management allowed us to study the integration both early on and after a substantial period of time. Longitudinal case studies typically start well after the merger and/or with much shorter time intervals between measurements. Finally we extend previous conceptualizations of shared identity and then develop implications for research and practice.

\section{The Social Identity Approach to M\&A}

Organizational identity has been conceptualized in different ways and from different theoretical perspectives (Haslam et al. 2003). It can be defined as members' collective and shared sense of who they are as an organization in terms of the characteristics collectively understood by the members to be central, distinctive and

\footnotetext{
${ }^{1}$ Given the sensitive nature of this research, the names and some details about organizations and individuals involved in the research have been changed.
} 
enduring (Albert and Whetten 1985). In other words, organizational identity is a 'relatively enduring state that reflects an individual's willingness to define him- or herself as a member of a particular organization' p. 382 (Haslam 2001). We refer to organizational identification as the individual's perception of the sharedness of this organizational identity (Ashforth and Mael 1989). Both concepts are grounded in social identity theory and self-categorization theory, which together help explain social behavior when individuals are not acting on the basis of their personal identities but as members of their group(s) in relation to members of other groups (Tajfel and Turner 1986; Turner et al. 1987). Personal identity, or "how am I different from him/her?", might become less salient in contacts with other groups. In such circumstances, individuals tend to define themselves in terms of their social identity shared with ingroup members.

Self-categorization theory provides a complementary perspective (Turner 1985; Turner et al. 1987). It describes the emergence of group-oriented behavior as a process of depersonalization. When a particular social identity is salient, an individual's self-perception tends to be based on attributes shared with other group members rather than individual characteristics. Various social identities for selfcategorization are available at a particular time (Brewer 1991), and individuals may choose to identify with groups that provide a distinctive and self-esteem enhancing identity. As a result, identity conflict might emerge when two clearly defined identities, in terms of "who are we?" co-exist, and compete to seek privilege (Corley and Gioia 2004). Identity conflict is likely to be exacerbated in situations marked by an unequal distribution of scarce resources such as power, prestige or wealth (Brewer and Kramer 1985; Tajfel and Turner 1986). On the other hand, organizational identification can positively contribute to the success of a company. Previous research demonstrates that highly identified employees show more positive work-related outcomes, such as the intention to remain in the organization, job satisfaction, work motivation, cooperative behavior (for a meta-analytic overview see: Riketta 2005), and readiness for change (Rousseau 1998).

\subsection{Constructing a Shared Post-Merger Identity}

Similar outcomes have been found in recent M\&A research (Bartels et al. 2009; van Dick et al. 2006). Shared identity has often been conceptualized as both content (Gaertner et al. 1993), i.e. perception of a common in-group identity, and process (van Dick et al. 2006), i.e. degree of identification with the new organization (c.f. Haslam et al. 2003 for conceptualization of shared identity in terms of content and process). Shared identity construction often takes place in conditions of a high uncertainty wherein members of pre-merger groups might search for a positive intergroup distinctiveness (Hogg and Terry 2000). Consequently, ingroup favoring might be evident leading to identity conflict (Terry et al. 2001). Identity conflict can be conceptualized as competing claims on who we are as the post-merger organization (Corley and Gioia 2004) and/or as seeking privilege for old identities (Albert and Whetten 1985). Research also suggests that identity conflict may lead to a failure to develop a shared post-merger identity (Meyer and Altenborg 2007), while others argue that it is the lack of a shared identity that leads to identity conflict 
(Amiot et al. 2007; Terry et al. 2001; Terry and O'Brien 2001). Some authors even argue that identity conflict might be a natural stage in shared identity construction (c.f. intractable identity conflicts; Fiol et al. 2009).

Prior longitudinal studies on M\&As have demonstrated that (pre-merger) identity conflict is unavoidable but may gradually decrease over time. In a quantitative study of a university merger, the impact of the pre-merger on the post-merger identification was dissipated over time (Gleibs et al. 2008). Interestingly, a longitudinal case study of a healthcare merger reveals that shifts from first having separate identities to later having shared identity might take place through an early constructed "transitional" future-focused identity (Clark et al. 2010). Also, a narrative case study conducted by Chreim (2007) confirms a possible convergence in interpretations of identity over time; at the early stage all groups viewed themselves as "losers" due to the need to compromise on their pre-merger reality and at the later stage pre-merger groups were able to reach convergence by embracing an "envisioned" future-focused identity.

\subsection{The Nature of Intergroup Dynamics}

While constructing a shared identity is considered to be necessary for successful M\&A outcomes, most prior research sought to determine the role of intergroup dynamics. Social identity theory, as applied in M\&A literature, predicts identity construction can be influenced by status and boundary permeability (Hogg and Terry 2000; Lupina-Wegener et al. 2011; Terry et al. 2001; Terry and O'Brien 2001). Status might result from the fact that one organization has a superior business (Giessner et al. 2006) or performance (van Knippenberg et al. 2002) as well as its position as the acquirer (van Dijk and van Dick 2009). Past research suggests that employees of the low-status group may have more difficulties embracing the postmerger identity (Terry et al. 2001). Employees of the low-status group might embrace the post-merger identity if boundaries are perceived to be permeable, while members of the high-status group tend to prefer boundaries to remain impermeable in order to secure their dominance (Terry et al. 2001). Indeed, whether status translates into an imbalance of influence in the merged organization depends on the actual merger pattern (Giessner et al. 2006). With regard to the merger pattern, the social identity approach finds two factors in intergroup dynamics to be important to members of low-status groups for coping with their disadvantaged position, namely stability and legitimacy; for an overview see (Ellemers 1993). Particularly, legitimacy has been found to result from the fit between desired and realized integration patterns (Gleibs et al. 2013). We highlight such differences in status and permeability that might impact members' perceptions of both stability and legitimacy, although space limitations restrict further discussion in this paper. Terry and O'Brien (2001) provided an excellent study on stability and legitimacy, and generally, to increase the legitimacy of a merger, managers would pay attention to the factor of perceived fairness (Gleibs et al. 2008; Gleibs et al. 2013).

Summing up, extensive research on M\&As has focused on identity construction and the nature of intergroup dynamics. Recent identity construction literature suggests that identity conflict might be a natural stage in building shared identity 
and can be overcome. Furthermore, the literature on the nature of intergroup dynamics reveals that status and boundary permeability can significantly impact shared identity development. However, it remains unclear how intergroup dynamics might change and how the latter may contribute to overcoming identity conflicts and to facilitating the development of a shared identity (Amiot et al. 2007; Clark et al. 2010). Moreover, issues contributing to intergroup dynamics have not yet been researched. We will address this important gap by investigating a subsidiary merger with an objective to answer the following two questions put forth at the beginning of this paper, namely (1) how do subsidiary intergroup dynamics shape the construction of a shared organizational identity? and (2) which issues contribute to these intergroup dynamics in subsidiary M\&As?

\section{Methodology}

To answer our research questions, we conducted a longitudinal in-depth case study. We followed and integrated categorizing and connecting analytical strategies (Maxwell and Miller 2008). Coding is a categorizing strategy focused on linking data segments, so we relied on pattern-matching coding to account for the role of emerging constructs in the merger (Doty and Glick 1994). Qualitative case study is a connecting strategy, and helps to capture the contextual information. Single-case studies are appropriate in longitudinal investigations of revelatory settings (Raukko 2009; Yin 2009). This international subsidiary merger is unique, because we started investigations 1 month before the integration took place, then we captured the entire post-merger integration. Alpha-Beta merger provided a rich context for understanding the changing nature of intergroup dynamics together with key issues shaping them. Indeed, a longitudinal case study design provides unique insights into how certain conditions change over time and towards a certain outcome (Soulsby and Clark 2011).

\subsection{Research Setting}

We investigated the merger of the Mexican subsidiaries of two European pharmaceutical companies starting with pilot interviews 1 month before postmerger integration began. Alpha-Corp, a large European multidivisional MNC acquired Beta-Pharma, a specialized research oriented company. The offer by Alpha was a white knight rescue from a prior hostile takeover attempt of Beta. The rationale for the merger was achieving synergies in $\mathrm{R} \& \mathrm{D}$, sales force and marketing operations. The merger was officially proclaimed to adopt a "best-of-both" approach as Alpha-Pharma-Alpha's pharmaceutical division and Beta-Pharma were considered to be market leaders before the merger.

The present case study is phenomenon-based and addresses issues that are relevant to management practice but underexplored in existing research (von Krogh et al. 2012). We started investigations in Alpha-Beta-Pharma at an early stage of the merger integration and we ended data collection with the integration concluded. The case was identified by the research team from the press, which reported on the public bid. We obtained permission for the study from the CEO of Alpha-Corp 


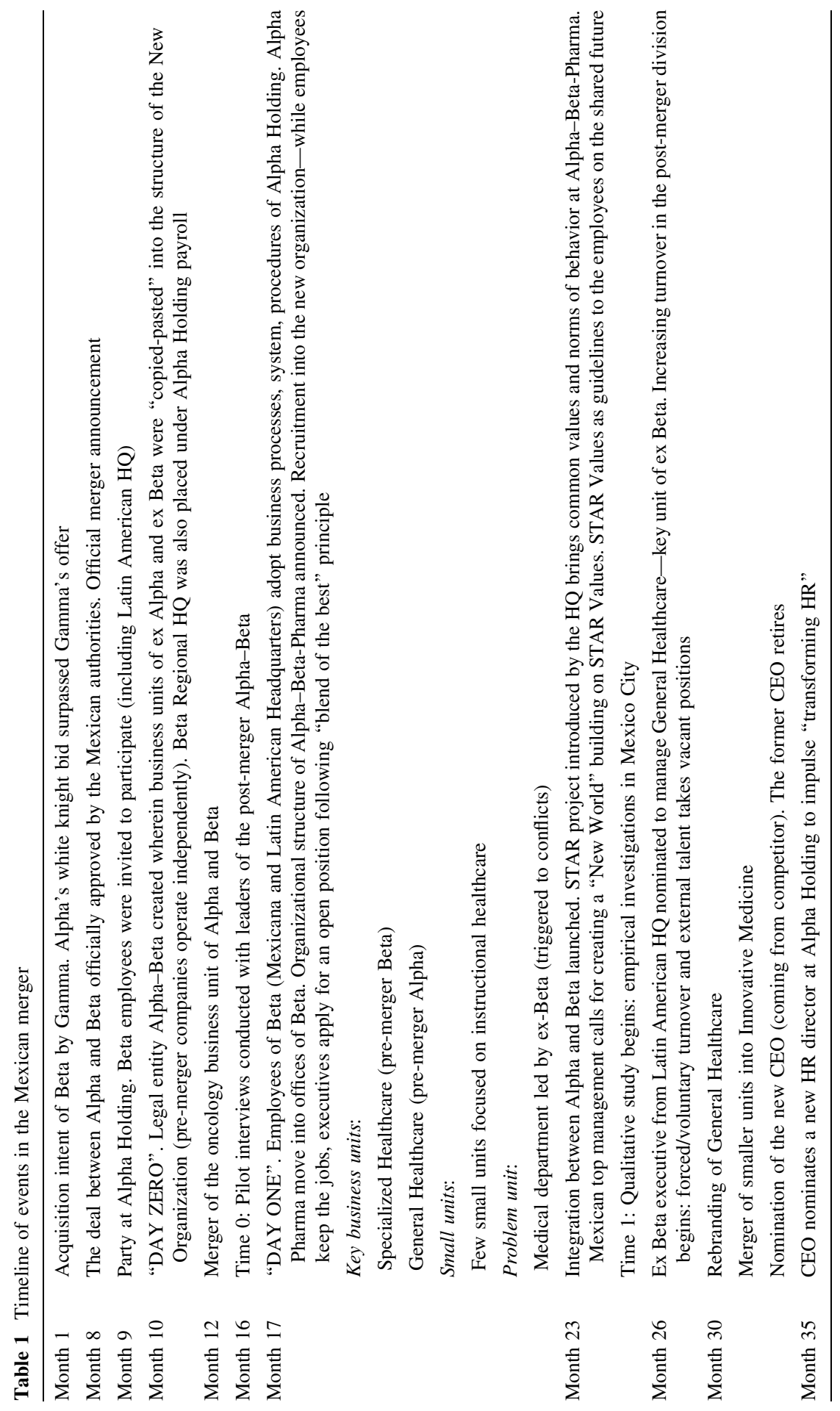




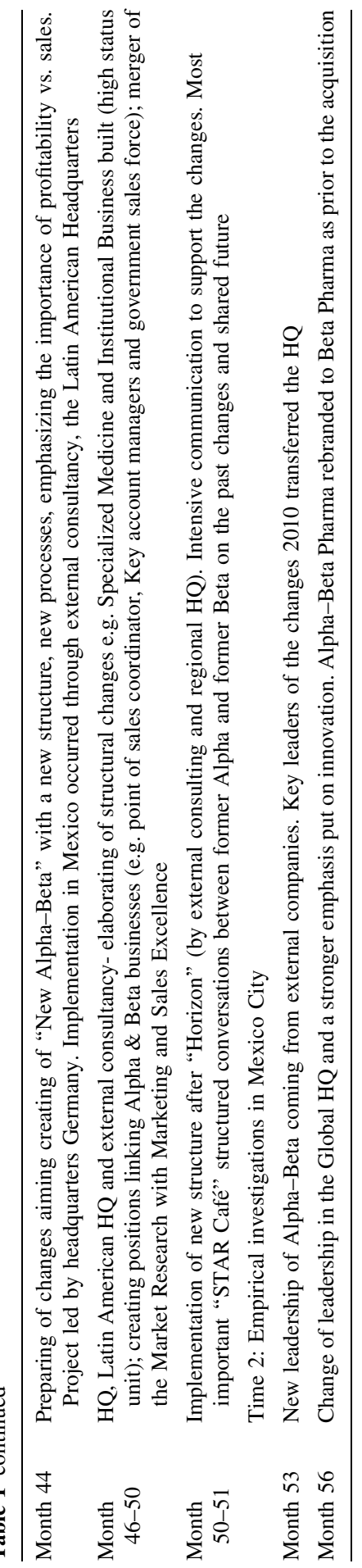


(based on research-oriented objectives). With her support, we submitted a study proposal to the Head Office to request authorization from the Vice President responsible for strategy. Table $1^{2}$ displays the chronology of events as well as our data collection points. We began with pilot data collection in "Month 16": 6 months after the "Day 0" (i.e. the legal merger implementation) and 1 month prior to the "Day 1" (i.e. post-merger integration). Specifically, in T0 we conducted seven telephone interviews with top management. Our objective was to get early insights into the integration and finalize the interview questions. Subsequently, we referred to temporal bracketing strategy to deal with rich qualitative data, while at the same time account for clear temporal break points to obtain distinctive units of analysis (Langley 1999). Therefore, we began Time 1 (T1) investigations in "Month 23 ", i.e. when actual managerial efforts to integrate Alpha and Beta employees were launched. This carefully selected time point allowed the study to capture early integration efforts. The first author spent over 3 weeks at the sites of Alpha and Beta. Her physical presence onsite resulted in interviews, observed interactions and informal discussions with employees. These informal discussions are a valuable method of data collection, and rare because employees are often concerned about confidentiality in M\&As settings. Trust was established with the informants through frequent contacts and personal relationships. Informal data was collected during daily lunch breaks shared with the employees and other exchanges at the site. However, we did not include quotes from informal talks as these exchanges were off record. This variety of methods in qualitative data collection allowed for capturing early integration efforts, intergroup dynamics and identity construction processes. Note that employees knew they were dealing with an academic researcher from Switzerland studying the merger. In the following months, integration was rather slow, with Alpha and Beta businesses characterized by a low but gradually increasing interdependence. Only in "Month 46" did a sudden increase of integration between Alpha and Beta took place, after new powerful stakeholders emerged and took the lead in Alpha-Beta Pharma. After learning of these developments, the first author returned to the empirical site in "Month 51": Time 2 (T2). We conducted 14 semi-structured, face-to-face interviews; 11 of these interviews were conducted with the same employees as in T1. All our interviewees in T2 worked in either Alpha or Beta before the merger. However, we were unable to interview all T1 informants in T2 as turnover was high. Specifically, 17 interviewees of T1 had left the company. Table 2 gives an overview of the premerger background of the interviewees. In addition to semi-structured interviews, discussions with employees in informal settings continued for more than a week. The researcher also attended in T2 a communication workshop with employees including a follow up social event. We also studied archival sources to triangulate existing data. Data collection ended at this time point, marking the end of continuity to pre-merger identities of Alpha and Beta, and the concluded post-merger integration. Specifically, between "Month 53-56", a significant change in strategy and leadership took place. Moreover, Alpha-Beta-Pharma rebranded to Alpha-

\footnotetext{
${ }^{2}$ In order to guarantee confidentiality of the studied organizations, we cannot provide exact dates of the merger.
} 
Table 2 Overview of pre-merger background of the interviewees

\begin{tabular}{lll}
\hline Pre-merger phase & 7 interviews with executives & 5 Alpha interviewees \\
& & 2 Beta interviewees \\
Post-merger phase I & 32 interviews with: & 17 Alpha interviewees \\
& 24 executives & 15 Beta interviewees \\
& 5 sales reps. (including group managers) \\
& 3 support & \\
Post-merger integration II & 14 interviews with: & 7 Alpha interviewees \\
& 11 executives & 7 Beta interviewees \\
\hline
\end{tabular}

Pharma as the dominant group was called prior to the acquisition. A new period for employees of then Alpha-Pharma began.

\subsection{Data Collection}

Alpha-Beta-Pharma was selected based on a critical case sampling approach, which enabled us to select a case that is rich in information (Miles and Huberman 1994; Yin 2009). The longitudinal merger provided insights into evolving intergroup dynamics and the dynamics of identity construction. We referred to purposeful sampling (Kumar et al. 1993; Lincoln and Guba 1985; Pratt 2009) and interviewed informants who had knowledge of managerial interventions and had experienced interactions with members from the other, pre-merger group. Our analysis is based on interviews with informants from the two main pre-merger sub-groups (AlphaPharma, and Beta-Pharma, including Beta Regional Head Office). We also interviewed top executives at Alpha-Corp Mexican Head Office who played a key role in the integration.

Face-to-face interviews lasted on average $60 \mathrm{~min}$ and phone interviews around 35 min. They were conducted in English with managers. Interviews with nonmanagerial staff were mainly conducted in Spanish by a Mexican scholar and three of the interviews were assisted by a simultaneous translator. All interviews were tape-recorded and transcribed. Detailed notes were taken directly after each interview and written notes were taken after informal conversations. Spanish audio files were transcribed and subsequently, translated into English. Summing up, we examined the merger of European MNC subsidiaries in Mexico as perceived by the informants over time. This approach involves inductive logic (Corley and Gioia 2004) to gain insights into employees' experiences of new situations and their subsequent different behaviors during the process (Langley et al. 2012). The verbatim data were organized, coded and analyzed using NVIVO software to keep track of emerging categories.

\subsection{Data Analysis}

We followed the grounded theory as a guideline for theorizing from process data to identify generative mechanisms. According to Corbin and Strauss (2008) process is 
"ongoing action/interaction/emotion taken in response to situations, or problems, often with the purpose of reaching a goal or handling a problem" (p. 96). Thus, we looked for conditions and circumstances that may help shape interactions and subsequent consequences. We simultaneously worked with raw data, emerging theory, and existing literature to provide an understanding of the process. We proceeded along the following steps:

First, we began with a first-order analysis based on the informants' own language (van Maanen 1979) while looking for conditions, interactions among actors and consequences (Corbin and Strauss 2008). Particularly, we had a provisionary coding "start list", and aimed to identify intergroup dynamics, issues shaping them, and consequences in terms of shared identity. Initially, codes had a purely descriptive character, for instance negative descriptions of outgroup, or statements on the degree of integration. These descriptive codes applied mainly to the first sets of field notes. Subsequently, these codes were re-examined for fit with the data and to avoid restrictions (Miles and Huberman 1994). Further descriptive codes were added as provided by the participants (Lincoln and Guba 1985).

Second, we moved to pattern-matching by constantly comparing our data with existing theories (Miles and Huberman 1994). We assembled data into a higherorder categories focusing on issues contributing to changing intergroup dynamics. This approach revealed new causal patterns in a single case study as a result of data analysis building on theoretical interpretations. We regularly compared the empirically based patterns with extant theory in order to "map" the codes and examine how they interconnect to uncover previously unknown relationships. Emerging relationships between concepts were recorded in memos along with the context information. As a result, our data analysis revealed the role of Head Office in facilitating changing intergroup dynamics - from seeking differentiation between pre-merger groups (T1) to reinforcing external boundaries (T2). This combination of the grounded theory and pattern-matching approach provides the basis for a rigorous collection and analysis of qualitative data by clearly delineating themes and aggregate dimensions. At the same time, flexibility in the search for new causal relationships over time was maintained (Ahammad and Glaister 2011), while building on existing constructs (Stahl et al. 2011).

Third, longitudinal data was analyzed using a three-staged approach to research on change (Pettigrew 1990): (1) tracking the context of changes (in the construction of identity); (2) uncovering conditions shaping the change over time; and (3) mapping interrelations between the context and action in shaping the change. Finally, we conducted "member checks with informants" to validate that our emerging model corresponds to experienced merger reality (Clark et al. 2010); we conducted two phone interviews with key players a few months after completing a draft data analysis (around 40 min each).

We used multiple approaches to meet the criteria for trustworthiness (Lincoln and Guba 1985) as applied to case study research (Yin 2009).

First, internal validity was ensured by reference to theoretical frameworks, which here included the process approach (Corbin and Strauss 2008) and social identity theory (Tajfel and Turner 1986). Linking cause and effect relations was possible by referring to a longitudinal method in the process approach (Vincze 
2013). An alternative data analysis approach that could be usefully applied would focus on linking data broadly defined with specific events and thus, reveal connections and causalities between emerging issues together with the generative mechanisms (Maxwell and Miller 2008; Van de Ven 1992). This would, however, require data collection guided by critical events associated with the merger integration. We chose pattern-matching coding because we were less concerned about how generative mechanisms or issues change over time. Instead we purposely referred to the grounded theory, accounting for conditions and circumstances which may help shape interactions and subsequent consequences (Corbin and Strauss 2008).

Second, to ensure construct validity, we triangulated the collected data through comparing interview results with inspection of internal documentation, press information and informal discussions during coffee or lunch breaks and observation. Third, to enhance reliability, we meticulously managed our data, including contact records, interview transcripts, field notes and documents as they were collected, by using a computer-based qualitative data management program. Also, we summarized each interview along emerging themes (created in memos), which we subsequently coded. Consequently, a clear chain of evidence was established when moving from our research findings to conclusions (Yin 2009). Fourth, we used peer debriefing, which entails the field investigator engaging another researcher, not involved in the study, to discuss emerging patterns in the data through her critical questions. Fifth and finally, the longitudinal single case study allows analytical generalization (Raukko 2009) and provides insights into an under-investigated temporal dimension of identity construction in circumstances of dramatic changes.

\section{Findings}

Figure 1 provides a coding scheme of the data structure of the findings. It depicts three main dimensions that emerged from our analyses (right side of the figure), as well as their constituent second order themes, and the first-order concepts. The overarching emergent dimensions include the context within which intergroup dynamics occurred together with its drivers and consequences.

\subsection{Merger Integration Started: Head Office Interventions at Time 1}

A few months after the merger agreement was signed between Alpha-Corp and Beta-Pharma, the post-merger division, Alpha-Beta-Pharma, was created at the global level. Beta-Pharma was focused on specialized medicine and Alpha-Corp was in charge for both pharmaceutical and non-pharmaceutical products.

\subsubsection{Designing Permeable Boundaries}

The Mexican subsidiary of Beta-Pharma, together with its Latin American Head Office were absorbed by Mexican Alpha-Corp and merged into its 
Statements of confirming "blending of the best" wherein top positions were filled according to possessed skills and not premerger origin of an executive

Descriptions of mixing professionally Alpha and Beta employees

Descriptions of global STAR values as communicated and reinforced by local top management

STAR café -implication of STAR values as discussed in teams of ex- Alpha and ex-Beta employees: changes after the merger, emotions on layoffs of colleagues, and reflections on the future

Descriptions of structural changes (new strategy) conducted by the Head Office and Latin Am. HQ

Statements on statements about layoffs

Descriptions of a type of culture change (work environment, decision making, business relationships)

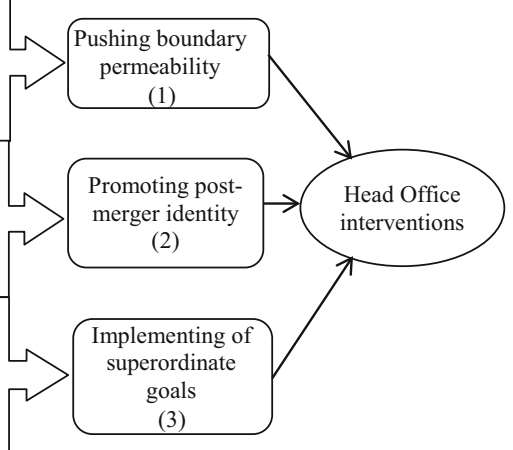

Statements of higher operational efficiency, a stronger market position, a larger size of in-group

Statements on inferiority of outgroup or their illegitimate superiority

Calls by group members for more influence, questioning of legitimacy of the "blending the best" approach

Commitment to post-merger organization: claims for needing both pre-merger groups to maintain competiveness

Positive descriptions of the outgroup in contributing to "who we are" after the merger

Psychological rejection of employees not identifying with the post-merger organization

Proactive calls for clarifications by HQ "where the ship is heading"

Comparisons of the post-merger organization to other, external stakeholders. Alpha/ Beta- equal status

Influence of others illegitimate; ex Alpha and ex Beta need each other to resist "outsiders"; calls for more influence of AlphaBeta Pharma in Mexico

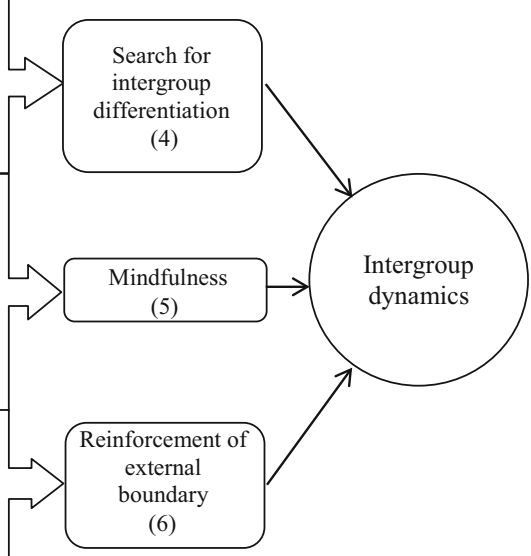

Two competing identity claims co-exist

Competing identity claims seek privilege in the post-merger organization

"who we are" - collective answer mutually incompatible

Descriptions of "who we are"/ "who are we becoming" as the post-merger organization

Commitment to STAR values

Statements demonstrating embracing of the post-merger identity

Comparisons of Alpha-Beta-Pharma to other, external stakeholders.

Statements on figuring out how post-merger organization is distinctive from significant others

Descriptions on figuring out how post-merger organization is distinctive from significant others.

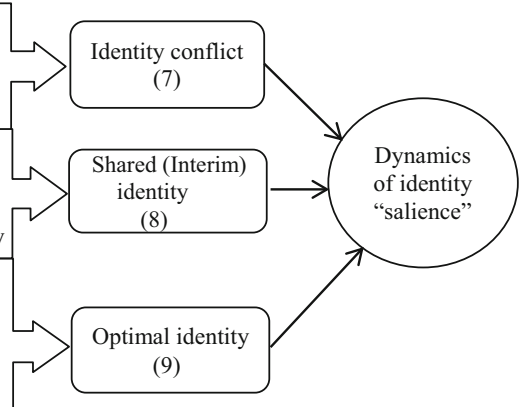

Fig. 1 Data structure

pharmaceutical division. Alpha-Pharma employees relocated to Beta-Pharma's site. Beta employees received new employment contracts preserving their remuneration and hierarchical levels. They were absorbed into Alpha-Corp corporate processes and both pre-merger businesses were preserved. Based on 
the "blending the best" principle dictated by the Global Head Office, top executives from both pre-merger organizations were requested to apply for an open position. Ultimately the key positions in Mexico were split between Beta and Alpha executives.

\subsubsection{Promoting Post-Merger Identity}

The newly selected top management team promoted construction of a "new" identity with an emphasis on "equal" relations between merging partners. The focus was on the success of Alpha-Beta-Pharma with a contribution from all the employees. The expectation was that a fast integration and thus, staying "ahead" of their sister Latin-American subsidiaries, would facilitate this "success" in terms of enhanced market leadership in the Mexican pharmaceutical industry. Moreover, following guidelines set by the Global Head Office, the top management team in Mexico promoted a new post-merger identity building on the following three "STAR" values: questioning the status quo, putting clients first, and being decisive. These three values were disseminated during workshops that were attended by Alpha and Beta employees separately.

\subsection{Intergroup Dynamics: Time 1}

In Alpha-Beta-Pharma, seeking intergroup differentiation became apparent, such as members from both pre-merger groups aiming for a privileged access to executive positions and other resources including benefits, social services, and the pre-merger way of running business. Privileged access was conceived to be result from ingroup superior pre-merger business and status. Indeed, differentiation first took place based on how business was conducted before the merger. Beta employees expressed difficulties finding themselves in the large Alpha-Corp, while Alpha-Pharma employees complained about Beta colleagues trying to change what they considered to be well-established and effective procedures. For example, an executive from Beta (+15 years seniority) stated:

Talking about utilities, EBIT, Beta was much bigger than Alpha. We had 3 extremely strong businesses, Alpha was also profitable, but Beta was more profitable. And, I would say, obviously, or ... fortunately, people like [mentions name of the head of Alpha-Pharma] or other people [Alpha executives] are willing to learn [from us].

In the same period, an Alpha manager (middle level, +15 years seniority; the informant was fired by $T 2$ ) stated:

This integration turned out to be too demanding and suffocating. There were days when we (Alpha) were saying, "Enough, please" because we had a lot of work. The fact of continuously having to train people (Beta), to explain how things work that definitely took a lot of our time. But, it was necessary. There were a lot of rebellious attitudes. And still, after we had explained how things 
should be done they (Beta) still went ahead with the ways things used to be done (before the merger).

Second, differentiation was based on the pre-merger status that the informants considered not sufficiently recognized in the post-merger organization. Specifically, as Beta members experienced difficulties with imposed business processes from Alpha, they experienced this "acquisition" as illegitimate. On the other hand, Alpha employees did not appreciate the "blending the best" merger approach and claimed such a "reverse takeover" to be illegitimate. For example, an Alpha executive (+15 years seniority; the informant left the merged company by T2) stated:

(Our) managing director is from Alpha [Pharma]. But, his boss [indicates the name, head of Regional Office] is from Beta. And, his boss is also from Beta. And, the next up guy is from Beta.

In the same period, a Beta manager (middle level, +5 years seniority; the informant left the merged company by T2) explained:

We have been trying to do changes, small ones, because we did not like to be perceived by them [e.g. Alpha] as just Beta but rather as a force to do something that they do, but differently. They ask us "how can this be possible? We have always done it this way and it works". It works for whom? What about some people inside the organization who do not like that?

Summing up, Alpha considered that their position as an acquirer should induce a high status and impermeable boundaries. Alpha informants called for more influence and privileged access to rare resources. On the other hand, Beta employees considered their pre-merger group to have a high status due to their innovative know-how, efficient process and friendly work environment. They called for the "blending the best" approach to be respected.

The search for differentiation described above was accompanied by mindfulness of organizational members (c.f. Fiol et al. 2009), i.e. the creation of new categories of meaning, openness to new information, and an implicit awareness of multiple perspectives. First, employees from both merging groups acknowledged the premerger successes of the other and the contribution of outgroup to the post-merger organization. For example, Beta employees claimed to appreciate becoming part of "Alpha" due to its larger share of the market, superior governmental relations and better-known brand. One Beta manager ( +15 years seniority; the informant left the merged company by T2) explained:

Beta was ranked much lower (indicates the number) in the Mexican market. Now, we are in the top. So, this is a very different position when we have to make commercial deals and negotiate with external parties. It is really very different to arrive as top listed to different institutions, hospitals or wholesalers.

On the other hand, Alpha employees considered their pre-merger organization to be less innovative and they were also attracted to Beta's employee-friendly management practices and sociable atmosphere. Calls for creating the "New 
Alpha-Beta-Pharma" emerged. Moreover, many interviewees suggested that their colleagues who did not accept the new reality should leave the company. An Alpha senior executive testified (+ 20 year seniority; the informant was fired by $T 2)$ :

We need to do what is best for Alpha-Beta-Pharma and finish our pre-merger history. Maybe we need to build a new story for the company. And for that, we need to find the best solutions: not "my solution" to create a new company. Because we are a new company!

\subsection{Dynamics of Identity Salience: Time 1}

Under such intergroup dynamics, Alpha-Beta-Pharma consisted of two separate groups with pre-merger identities salient. While members of both groups perceived their pre-merger organization to have been "successful" and distinctive from sister divisions in Latin America, identity conflict was apparent. Beta employees defined their pre-merger organization as small in size, successful as an industry leader in terms of innovative drugs and high profitability, having efficient management procedures, being employee focused and having a great team spirit. Alpha defined their pre-merger organization in the following terms: the acquirer, huge and expanding; and a successful industry leader (in terms of high volume of sales) with a paternalistic management approach. Alpha-Beta-Pharma was viewed positively but through lenses of the past, pre-merger realities. Alpha employees attributed the successes of Alpha-Beta-Pharma to their pre-merger identity of "medications with a high volume of sales". Beta employees attributed these successes to their pre-merger features, i.e. being "highly profitable, innovative". An Alpha middle manager ( +15 years seniority; the informant was fired by T2) explained:

What is Alpha-BetaPharma? We don't need "Beta"! When Alpha bought Beta and they included the name "Beta" we asked "Why? Beta didn't buy Alpha. We don't need to re-brand!"

At the same time a shared (interim) identity reflected "success" as well as common goals and the perceived utility of a post-merger organization. Specifically, informants claimed the post-merger division to be a pharmaceutical leader with a high quality product and advanced research capabilities. A potential for future growth due to synergies achieved was stressed. An Alpha executive stated $(+15$ seniority; the informant was fired by T2):

We are in the top worldwide, with the great world powers and that makes me proud, with a lot of commitment since we have to contribute to the further successes of Alpha-Beta-Pharma.

Moreover, employees of both merging groups embraced the interim identity for "New Alpha-Beta-Pharma" as presented by the top management ("STAR values"). A Beta middle manager stated (+10 years seniority; left company by T2): 
I believe that today we have projects like the "STAR" where we are seeing that the company is really focused in joining these two ways of thinking, and today, I think we are reaching a synergy. (Market and financial) results we saw last week are very encouraging and also the projects we are involved in are very large for what now is Alpha-Beta-Pharma. We aren't talking only about Alpha or about Beta. Now it is Alpha-Beta-Pharma and we need to see it as such.

\subsection{Merger Integration Completed: Head Office Interventions at Time 2}

At time 2, Global Head Office and Regional Head Office gained more influence on Alpha-Beta-Pharma's operations in Mexico.

\subsubsection{Setting Superordinate Goals}

New strategy was set forth that was neither "Alpha" nor "Beta" but built on the strengths of both. First, the Global Head Office initiated changes in the top management team. Most importantly, the former CEO retired and a new CEO of Alpha-Corp Mexican Head Office was nominated from the Global Head Office. The new CEO replaced the standing Human Resource (HR) director with an executive coming from outside in order to transform the HR function. Also, the director of the key business of Alpha-Pharma was nominated from the Regional Head Office (pre-merger Beta). Second, the new top management team at AlphaCorp Mexican and at Global Head Office initiated changes to implement a new strategy for Alpha-Beta-Pharma to focus on institutional customers: public and private hospitals. The key business units of Alpha (general healthcare) and Beta (specialized healthcare), along with HR, marketing and sales were combined. This unit grew from six-employees at $\mathrm{T} 1$ to 120 employees at T2, taking the best employees from both general healthcare (pre-merger Alpha-Pharma) and specialized healthcare (Beta-Pharma). As a result, both pre-merger businesses of Alpha and Beta lost status, while the new institutional business unit had high status. As Alpha and Beta employees were re-shuffled into the new, high status unit, and additional $20 \%$ of jobs were eliminated as part of a cost-cutting strategy of the Head Office. All told, between T1 and T2, $32 \%$ of Alpha and $41 \%$ of Beta employees left the company and newcomers represented $35 \%$ of the employees in the post-merger division.

\subsubsection{Promoting Post-Merger Identity}

Changes described above were accompanied by managerial interventions such as "STAR café" workshops. During the workshops, small groups of former Alpha and Beta employees, along with newcomers, were encouraged to discuss how they experienced the changes and how they saw giving up past reality to embrace the "New World" recently created. The messages on post-merger identity were strongly supported by the top management of the post-merger division. Three leaders in particular were considered to have played a key role in shaping the identity of the 
post-merger division: the managing director (Alpha), the head of the generic unit (Beta) and the head of the "specialized, institutional business" unit (who joined Alpha just before the merger).

\subsection{Intergroup Dynamics: Time 2}

\subsubsection{Delineating of External Boundary}

While pre-merger memberships were no longer important, members focused on outgroup outside the post-merger organization. The informants called for more autonomy from the various Head Offices (Mexican, Regional and Global). The differentiation took place based on the post-merger status wherein members of Alpha-Beta Pharma sought recognition from Head Office (Mexican, Regional and Global). Particularly, they viewed influence of the Regional Head Office in the postmerger division as illegitimate. Complaints mainly concerned changes for AlphaBeta-Pharma in Mexico. Interviewees claimed that instead other subsidiaries in Latin America and also Alpha-Corp Mexico Head Office should go through changes as their results were viewed as worse. Overall, the sudden high status of the Regional Head Office was not expected. In fact, in T1 the Regional Head Office was expected by members of both Alpha-Beta Pharma and Alpha-Corp Mexico to end its existence as its utility was judged low. One Alpha manager complained (middle level, +15 years seniority):

All people in the Alpha-Beta-Pharma World wonder why the Regional Head Office exists. Their role is not clear. They are like luxurious auditors. They set the rules, but they are not responsible for results. They threaten the results. Regional Head Office is like a god... they judge the performance of our company, they set the rules, they set the procedures, they establish the economic goals. But, they don't work... really. They are watching... what the companies are doing. They are like controllers of our company. They decide... Sometimes, they don't have the position to know the market, position of the country. They are not in the country.

\subsubsection{Mindfulness}

Alpha-Beta-Pharma members called the Global Head Office for clarifications on the future of the post-merger division, which was considered successful in terms of market leadership and financial results. Simultaneously, employees sought interactions between members of ex-Alpha and ex-Beta. Criticisms towards colleagues perceived as protecting pre-merger reality or rejecting the identity of the postmerger organization became evident. In this context, $32 \%$ of Alpha and $41 \%$ of Beta employees left the company and newcomers represented $35 \%$ of the employees in the post-merger division. Even more, Alpha informants supported the forced departure of their pre-merger highly respected leaders. An Alpha middle manager explained $(+20$ years seniority): 
Romeo and Ana Maria ${ }^{3}$ were people who illustrated for me the spirit of what has been really happening. And he, Romeo got a really very good position, but he never understood the "New World". He would get angrier and angrier. And, I don't know why... he was not able to digest that. So employees like him have had to leave the company. .... Romeo and Ana Maria, both in leadership positions, never understood what was going on. Finally, it was impossible to sustain them. It was much better for them and for the organization.

Beta informants related observations in the same vein, for example a Beta group manager said (info on seniority is not available; was not interviewed in T1).

I consider that they are equal (to us). The merger took place based on an international negotiation wherein it really does not matter who bought whom. What is important is that today we are one. And that now, we have got to grow on this base as a starting point.

\subsection{Dynamics of Identity Salience: Time 2}

\subsubsection{Shared (Interim) Identity}

Alpha-Beta-Pharma was perceived to become a "New World" reinforcing calls that emerged in T1 for creating the "New Alpha-Beta Pharma". At this stage, premerger identities (based on pre-merger successes, or efficiency vs. bureaucracy) became less salient. Employees demonstrated their belonging to the "New AlphaBeta-Pharma", which they now defined as successful, research intensive, open to change and future oriented. Overall, interviewees claimed Alpha-Beta-Pharma to be a united and integrated team of Alpha, Beta and newly hired employees. A Beta executive ( +20 seniority) explained:

I think the merger is no longer an issue. Still people feel their past they are coming from. But, I wouldn't say that this (past) is impacting very much their identity. After all the changes they had gone through... This also makes you more united.

Also, an Alpha executive described (+5 seniority):

I think we are in the same ship and we are going to the same place. I think, in the future, we will remain one company. We identify with the same company independently of the past, before the merger.

\subsubsection{Optimal Identity}

Alpha-Beta-Pharma was defined in contrast to a new outgroup, namely Global/ Regional Head Offices. First, interviewees considered themselves as an autonomous organization and not as a division. Members of Alpha-Beta-Pharma also

\footnotetext{
${ }^{3}$ Fiction names have been given to respect the privacy of employees (both from pre-merger Alpha).
} 
complained about not being recognized by the Head Office for their post-merger successes and about being treated poorly in comparison to the other Mexican divisions of Alpha and across Alpha-Beta-Pharma Latin American subsidiaries. An Alpha executive (+20 seniority) stressed the successes of Alpha-Beta-Pharma:

We [Alpha-Beta Pharma in Mexico] are most successful. And, if we are successful everybody [Mexican, Regional, Global Head Office] is happy in the organization. And, if there is nothing coming out, we have a problem. But on the other side, it is difficult to explain to a big group that we have also been successful in difficult times (interview refers to changes which were difficult) despite which we grew in the Mexican pharmaceutical market.

A Beta executive (+20 seniority; informant was not interviewed in T1) explained:

All the changes after the merger have been realized at Alpha-Beta-Pharma! No one of the other divisions has been submitted to critical changes and they should... and they should (have been concerned by the changes). Now, you ask me ... we have already started mission 2015. Once again, another push, another change and that will also be the critical for Alpha-Beta-Pharma. Why aren't other subsidiaries submitted to changes?

\subsection{Synthesis}

At T1, the present case followed an "integration-proportionally" pattern (see Giessner et al. 2006 and Gleibs et al. 2013 for a framework on integration patterns) wherein Alpha's dominance was related to its "acquirer" status-and Beta's influence in the post-merger organization resulted from its status as being innovative, modern, and dynamic with outstanding leadership. While pre-merger identities were salient, employees embraced a shared (interim) identity considered as a continuation of the pre-merger realities. By T2, the "transformation" had occurred wherein status asymmetries were removed, external boundaries were reinforced and a new outgroup emerged: Head Offices and other Latin American subsidiaries. The post-merger organization in Mexico was claimed to have become a "New World" which was unrelated to the pre-merger identities. The discussion section outlines changes from $\mathrm{T} 1$ to $\mathrm{T} 2$ with a focus on conditions under which intergroup dynamics change over time and how they shape the construction of a shared organizational identity.

\section{Discussion}

Our longitudinal in-depth case study provides insights into the relatively underresearched and temporal dimension of identity construction in circumstances of dramatic changes. Specifically, the results allowed to address the research questions we put forward at the outset (1) how do subsidiary intergroup dynamics shape the 
construction of a shared organizational identity? and (2) which issues contribute to these intergroup dynamics in subsidiary M\&As?. In the example of the Mexican subsidiary merger, we contribute to research on identity construction over time (T0; 2007, T1; 2008, T2; 2010). The study took advantage of a rare opportunity that includes prior knowledge of the merger and permission to follow-up until postmerger integration concluded. Though past research on M\&As provides interesting insights into shifts from separate pre-merger identities to shared post-merger identity (Chreim 2007; Clark et al. 2010), how identities are informed by intergroup dynamics over time has not been explored.

In this section, we will first discuss shifts of identity salience along decreasing identity conflict and the construction of a shared identity. Second, we will point to the role of outgroup - outside of the post-merger organization-in informing intergroup dynamics. Finally, we will present a concept of optimal shared identity, which takes a broader, stakeholder approach to constructing organizational identity.

\subsection{Shifts of Identity Salience}

In $\mathrm{T} 1$, despite identity conflict, shared interim identity emerged reflecting the common goals of the post-merger organization (what Rousseau 1998, calls 'situated identification'). Such an identity was interim, facilitating multiple interpretations of what the post-merger organization was becoming, but remaining ambiguous enough not to threaten members from both pre-merger groups (Clark et al. 2010; Corley and Gioia 2004). Given the "blending of the best" approach to the integration, as imposed by the Head Office, pre-merger groups were encouraged to negotiate their contribution to the post-merger organization. Indeed, employees of both merger groups sought to prove their added value in the post-merger organization while trying to best reflect the new identity (Mummendey and Wenzel 1999). This echoes findings of Haslam et al. (2003) that highlight the importance of subgroup differentiation in the early stage of identity construction in order to subsequently promote a shared identity. Thus, identity conflict allows for asserting pre-merger identities, which in turn might provide organizational members with a sense of identity continuity, and post-merger identity may develop new, distinctive features (Fiol et al. 2009; Iyer and Jetten 2011). As a result, pre-merger identities might gradually become less salient, conceding space for the post-merger identity to develop.

Furthermore, shared interim identity at T1 contributed to positive outcomes at T2. These results extend a qualitative study conducted by Clark et al. (2010) on interim organizational identity in the early phase of M\&A integration. In our study, members not sharing identity developed at the early stage of the integration became ostracized by the members who claimed to protect the future of the post-merger organization. As a result of these pressures, some employees decided to leave (see the "victim" approach in Langley et al. 2012) and were replaced by newcomers who secured their membership through identification with the post-merger organization. In fact, the literature confirms that a loss of respect by group members might result in voluntary departures of those who refuse to identify with the organization, in contrast to newcomers who tend to embrace organizational 
identity to gain acceptance (Branscombe et al. 1999). Also, in line with the M\&A literature (Buono and Bowditch 1989), our analysis indicates that "merger survivors" gradually let go of the past and together with newcomers embrace the new post-merger identity. In the studied merger, shared interim identity, which emerged at T1, was further reinforced over time. More specifically, at T1 employees claimed becoming a "New World". Subsequently, over the next 36 months, this interim identity was reinforced and from it ultimately emerged the "New AlphaBeta-Pharma". The interim identity can be transitional, which allows pre-merger identities to become less salient.

Summing up, our findings suggest that without a shared (interim) identity at the early stage of integration, identity conflict might instead get in the way of the further development of a shared identity.

\subsection{Intergroup Dynamics: Role of Outgroup Outside the Post-Merger Organization}

In the result of the Global Head Office interventions, the post-merger division moved from the "integration-proportionally" in T1 to the "transformation" pattern in T2 wherein new post-merger identity was constructed (Giessner et al. 2006). The construction of a shared identity was facilitated by the Global Head Office, which reduced status asymmetries between merging groups and reinforced external boundaries of the post-merger division. While in T1, status differences were sought by pre-merger group members, and by $\mathrm{T} 2$, employees predominantly searched for status differences from the new outgroup i.e. the new "them": Head Office and other Latin American subsidiaries. In the same vein, boundary permeability changed over time such that who is in and who is out evolved over time. While boundaries were permeable at T1, by T2 "troublemakers" who rejected or did not fit into the new identity left and were replaced by newcomers.

With removed status asymmetries, permeable boundaries and the creation of the new outgroup outside the post-merger division, identity conflict present in $\mathrm{T} 1$ decreased and both pre-merger groups were integrated by T2. Alpha-Beta-Pharma was perceived to become a "New World" building on calls that emerged in T1 (mindfulness) and reinforced with superordinate goals (institutional healthcare) in T2. The identity conflict moved on to the next level with relation to outgroup outside the post-merger organization but within the MNC and namely Latin American subsidiaries, and the Head Offices. This finding makes three important contributions to M\&A literature and the social identity theory.

First, our findings help make an important contribution to the stakeholder approach to organizational identity construction. How different stakeholder groups jointly construct identities remains under researched by M\&A scholars. The stakeholder approach views organizational identity as "emerging from complex, dynamic, and reciprocal interactions among managers, organizational members, and other stakeholders" p. 43 (Scott and Lane 2000). Our data analysis reveals difficulties that managers might face in remaining loyal to conflicting demands of the Head Office and the subsidiary. Thus, members of Alpha-Beta-Pharma shifted focus towards a search for differentiation from other Latin American subsidiaries 
and Head Office. Conflicting demands might also explain personal changes in the top management team in the Mexican subsidiary which were reinforced by the Regional Head Office. The latter moved from a low (t1) to a high status (t2). The current study is to our knowledge the first to incorporate the changing status of powerful stakeholders, i.e. merging organizations, Regional/Global Head Office and subsidiary managers. Although the longitudinal study of a merger by Rouzies (2011) reveals that status might change over time between pre-merger groups, we provide insights into (1) who is ingroup and outgroup changes, and (2) how their respective status evolves over time.

Second, our findings shed light on an underexplored issue of identity construction in the context of organizations nested in larger structures (Gioia et al. 2010), such as a subsidiary within an MNC facing radical change (Blazejewski and Dorow 2003; Clark and Geppert 2011; Lupina-Wegener 2013). Past research has shown that conflict between Head Office and subsidiary management might hamper postmerger identity construction (Clark and Geppert 2011). Our findings extend these insights by demonstrating how Regional/Global Head Office can help reduce premerger identity conflicts on the one hand but can lead to the perception of the MNC as a new outgroup on the other hand. Particularly at the later stages of integration, search for distinctiveness of the post-merger subsidiary from the new outgroup may increase the risk that identification with the post-merger subsidiary remains at a situated level. Our study is one of the first to reveal a changing impact of Head Office managerial interventions in the subsidiary over time.

Third, we elaborate and fine-tune the reigning definition of a shared identity construction in M\&As. We will build on the stakeholder approach to organizational identity (Scott and Lane 2000) and optimal distinctiveness theory (Brewer 1991). According to optimal distinctiveness theory, developed by Brewer (1991), social identity ought to satisfy members' needs to belong to the organization as well as their needs to differentiate from the other groups; "social identity can be viewed as a compromise between assimilation and differentiation from others, where the need for deindividuation is satisfied within in-groups while the need for distinctiveness is met through intergroup comparisons": 477. Otherwise, it becomes impossible to ensure the loyalty of the members and other negative work-related outcomes might follow (Branscombe et al. 1999). We extend optimal distinctiveness theory which mainly focused on identity at the individual level. We coin the group level concept of an optimal shared identity (OSI). OSI allows for moving beyond post-merger organization and accounts for interactions with outgroups outside the post-merger organization. More specifically, we define optimal shared identity as the members' shared belonging to the post-merger organization and to the MNC (on the global or regional level) in the face of salient outgroups. Thus, OSI comprises (1) identification with the post-merger subsidiary, (2) identification with both premerger organizations and also the overarching, bordering entities such as the Head Office and it is (3) accompanied by salient outgroup(s) external to the MNC such as competitors and other external stakeholders. According to our knowledge, our paper is the first attempt to move beyond post-merger identity and to account for interactions with external stakeholders. OSI facilitates (1) deindividuation within post-merger subsidiary, (2) sufficient internal assimilation of the post-merger 
subsidiary within the MNC and (3) external differentiation from salient outgroup(s) external to the MNC. Consequently, positive work related outcomes in the post-merger subsidiary can be achieved.

In order to explain a dynamic character of OSI, we follow Vora and Kostova (2007) who have developed an elaborate model of dual organizational identification in the context of MNCs. According to their model, and confirmed by an empirical study, managers' identification with both the subsidiary and the Head Office lead to the best outcomes in terms of subsidiary managers' effectiveness and role fulfillment (Vora and Kostova 2007; Vora, Kostova and Roth 2007). In our context, we also assume that dual identification with both Mexican subsidiaries after the merger may lead to the best outcomes and this may be-for a short period of time-enhanced by the simultaneous emergence of a salient outgroup such as the Global/Regional Head Office. Thus, the identity patterns in the Mexican merger wherein high intragroup similarity based on pre-merger distinctiveness was reached at the final stage of the post-merger integration can be considered as a step towards building an optimal shared identity. However, Mexican post-merger subsidiary has not embraced an OSI with a well-defined, deeply embedded content c.f. deepstructured identity (Rousseau 1998). We argue that although Head Office or other subsidiaries becoming an outgroup may facilitate identity construction at the subsidiary level in the early stage of post-merger integration, ultimately there is a need for a shared identity to incorporate and unite the division on the national, regional and global levels. Indeed, identification with the MNC (Head Offices, reference subsidiaries) needs to be additionally embraced together with a focus on salient outgroups external to the MNC to achieve optimal shared identity.

It is apparent that OSI is dynamic and it can only be sustained if all stakeholders in identity construction make continuous efforts to align the specific subsidiary goals and interests with the overall MNC's vision and mission on global and regional levels. Ullrich et al. (2005) have claimed that the main task of managers after an integration is to provide a sense of "projected continuity", that is to know why the change process (here: the merger) is necessary to help the post-merger organization survive and grow in the future. In the same vein, we believe that OSI needs to remain somewhat flux to account for dynamics both within the MNC (such as emerging diversity in staff due to the merger or changes in strategy) and outside (such as new competitors or the emergence of new markets). Such an optimal shared identity might still evolve over time but simultaneously it provides members with the necessary continuity (Albert and Whetten 1985; Lupina-Wegener et al. 2014; van Knippenberg et al. 2002). Finally, it is important to pay attention to the fact that the concept of an optimal shared identity is not limited to an M\&A context and might be relevant in other organizational restructuring efforts. Thus, our findings might also make a contribution to the organizational change literature in general.

\subsection{Managerial Implications}

The case demonstrates the importance of managerial interventions in decreasing identity conflict and promoting a shared identity. Global Head Office started by communicating a clear vision of the potential synergies to be gained through the 
merger and by proclaiming the approach as "blending the best". Furthermore, Head Office demonstrated that everyone was to have a role and that there would be no ingroup favoritism. All management jobs were thus opened and reallocated, apparently on the "best of both" basis. Although Beta-Pharma was "absorbed" into the Alpha Latin American Head Office, the new division was housed in Beta facilities and followed the "integration proportionally" pattern (Giessner et al. 2006). These decisions and events provided symbolic reinforcement of "integrative equality" (Vaara et al. 2003). Finally, Global Head Office defined the new "STAR" values and created workshops to promote the new identity. Unfortunately, employees of Alpha and Beta attended these workshops separately, which might have reinforced premerger identities. Although in the "transformation pattern" a "New Alpha-BetaPharma" emerged and it was perceived to be united and successful, but insufficiently appreciated by Head Office and lacking autonomy. Thus, managers need to be aware that identity conflict and shared identity development may proceed in stages and evolve through intra- and intergroup dynamics over time. Management therefore should encourage efforts to differentiate but also set the guidelines and values so that the global MNC identity can be coherent.

\subsection{Limitations and Directions for Future Research}

The first limitation results from relying on qualitative case study methodology. We solely refer to an analytical generalization focused on developing avenues for further research-rather than generalizing to a larger universe. One possibility for future research would be to conduct a mix-method, multiple-embedded case study to compare the construction of shared identity at the Head Office level as well as among different subsidiaries. Future research might also address the role of the Head Office in the process of constructing a shared organizational identity. At the early stage Head Office interventions might help construct a shared organizational identity in the subsidiary, but at a later stage, Head Office interventions might delay the construction of an optimally shared identity in the post-merger subsidiary. There might be an inverted U-shaped relationship between Head Office interventions and identity construction over time. Under which circumstances Head Office has a positive or negative impact on shared identity construction in a post-merger subsidiary should be further investigated.

Second, would be important to better understand "merger victims" over a longer time-span; in our study informants in T2 claimed their merger was successful in terms of market leadership and financial results. However, what about the $30 \%$ of employees who left the company within 3 years? Would they share this positive assessment of the merger? As we interviewed "merger victims" only in T0 and T1, we are only partially able to explain why many employees were not able to embrace a post-merger identity and left the organization. Future research interviewing individuals who left after the merger is highly desirable but it is certainly a challenge for researchers to gain access to these employees.

Third, one could rightly argue that a study looking at three points in time would not really provide a process perspective of the development of a shared identity but presents a change in state from pre- to post. Although we believe that any longitudinal approach is an advantage over studies based only on the post-merger, 
we agree that a more fine-grained approach would be desirable with, for instance, quarterly measurements of change in pattern and events associated with change. We do believe, though, that a qualitative approach such as the one presented here has the advantage of allowing participants to present the change that they experienced in an evolving way. In fact, the interview informants have talked about the process from the "old" to the "new" identity, providing insights into underlying intergroup dynamics. However, future investigations might want to further investigate drivers and inhibitors to intergroup dynamics referring to such analytical strategies that could provide more contextual, event related information. This approach may help detect connections and causalities between issues contributing to intergroup dynamics over time and thus, reveal unexplored generative mechanisms in the integration processes going beyond the conditions and consequences. Finally, it is important to note that capturing the context might be particularly challenging in cross-border M\&As, which often imply interviews in more than one language and thus, translation is required. In our study, some interviews were conducted in Spanish, and translation into English posed some risk of losing some contextual information.

\section{Conclusions}

Our longitudinal study contributes to the literature regarding identity construction in M\&As. We provide insights into conditions under which subsidiary intergroup dynamics change over time during interactions between internal and external stakeholders. Specifically, who is ingroup and outgroup changes over time and how their respective status might evolve. We have provided an in-depth case study of a merger of Mexican subsidiaries of two European MNCs with a time span of 3 years from the beginning of the merger integration. Although identity conflict decreased through changes in subsidiary intergroup dynamics (boundary permeability and status equalization), a strong focus on outgroup inside the MNC delayed the creation of an optimally distinctive and deep-structured identity. Indeed, the process of identity construction must be considered to be dynamic and influenced by changing stakeholders, as well as boundaries and status between them. In this way perhaps in the process of identity construction, shared identities can be considered to be interim, continuously constructed.

Acknowledgments We would like to thank MIR editor Joachim Wolf and the two anonymous reviewers for their constructive comments.

\section{References}

Ahammad, M. F., \& Glaister, K. W. (2011). Postacquisition management and performance of crossborder acquisitions. International Studies of Management and Organization, 41(3), 59-75.

Albert, S., \& Whetten, D. A. (1985). Organizational identity. Research in Organizational Behavior, 7 , 263-295.

Amiot, C. E., Terry, D. J., \& Callan, V. J. (2007). Status, equity and social identification during an intergroup merger: a longitudinal study. British Journal of Social Psychology, 46(3), 557-577. 
Ashforth, B. E., \& Mael, F. (1989). Social identity theory and the organization. Academy of Management Review, 14(1), 20-39.

Bartels, J., Pruyn, A., \& de Jong, M. (2009). Employee identification before and after an internal merger: a longitudinal analysis. Journal of Occupational and Organizational Psychology, 82(1), 113.

Blazejewski, S., \& Dorow, W. (2003). Managing organizational politics for radical change: the case of Beiersdorf-Lechia S.A., Poznan. Journal of World Business, 38(3), 204-223.

Branscombe, N. R., Ellemers, N., Spears, R., \& Doosje, B. (1999). The context and content of social identity threat. In N. Ellemers, R. Spears, \& B. Doosje (Eds.), Social identity: context, commitment, content (pp. 35-58). Oxford: Blackwell Science.

Brewer, M. B. (1991). The social self: on being the same and different at the same time. Personality and Social Psychology Bulletin, 17(5), 475-482.

Brewer, M. B., \& Kramer, R. (1985). The psychology of intergroup attitudes and behavior. Annual Review of Psychology, 36(1), 219-243.

Buono, A. F., \& Bowditch, J. L. (1989). The human side of mergers and acquisitions-managing collisions between people, cultures and organizations. San Francisco: Jossey-Bass Publications.

Buono, A. F., Bowditch, J. L., \& Lewis, J. W. (1985). When cultures collide: the anatomy of a merger. Human Relations, 38(5), 477-500.

Chreim, S. (2007). Social and temporal influences on interpretations of organizational identity and acquisition integration: a narrative study. The Journal of Applied Behavioral Science, 43(4), 449-457, 459-463, 465-471, 473-480.

Clark, E., \& Geppert, M. (2011). Subsidiary integration as identity construction and institution building: a political sensemaking approach. The Journal of Management Studies, 48(2), 395-416.

Clark, S. M., Gioia, D. A., Ketchen, D. J., \& Thomas, J. B. (2010). Transitional identity as a facilitator of organizational identity change during a merger. Administrative Science Quarterly, 55(3), 397-438.

Corbin, J., \& Strauss, A. (2008). Basics of qualitative research: techniques and procedures for developing grounded theory. London: Sage.

Corley, K. G., \& Gioia, D. A. (2004). Identity ambiguity and change in the wake of a corporate spin-off. Administrative Science Quarterly, 49(2), 173-208.

Doty, D. H., \& Glick, W. H. (1994). Typologies as a unique form of theory building: toward improved understanding and modeling. Academy of Management Review, 19(2), 230-251.

Ellemers, N. (1993). The influence of socio-structural variables on identity management strategies. European Review of Social Psychology, 4(1), 27-57.

Fiol, C. M., Pratt, M. G., \& O’Connor, E. J. (2009). Managing intractable identity conflicts. Academy of Management Review, 34(1), 32-55.

Gaertner, S. L., Dovidio, J. F., Anastasio, P. A., Bachman, B. A., \& Rust, M. C. (1993). The common ingroup identity model: Recategorization and the reduction of intergroup bias. European Review of Social Psychology, 4(1), 1-26.

Giessner, S. R., Viki, G. T., Otten, S., Terry, D. J., \& Täuber, S. (2006). The challenge of merging: merger patterns, premerger status, and merger support. Personality and Social Psychology Bulletin, 32(3), 339-352.

Gioia, D. A., Price, K. N., Hamilton, A. L., \& Thomas, J. B. (2010). Forging an identity: an insideroutsider study of processes involved in the formation of organizational identity. Administrative Science Quarterly, 55(1), 1-46.

Gleibs, I. H., Mummendey, A., \& Noack, P. (2008). Predictors of change in postmerger identification during a merger process: a longitudinal study. Journal of Personality and Social Psychology, 95(5), 1095-1112.

Gleibs, I. H., Täuber, S., Viki, G. T., \& Giessner, S. R. (2013). When what we get is not what we want: the role of implemented versus desired merger patterns in support for mergers. Social Psychology, 44(3), 177-190.

Haslam, A. (2001). Psychology in organisations: the social identity approach. London: Sage.

Haslam, S. A., Postmes, T., \& Ellemers, N. (2003). More than a metaphor: organizational identity makes organizational life possible. British Journal of Management, 14(4), 357-369.

Hogg, M. A., \& Terry, D. J. (2000). Social identity and self-categorization processes in organizational contexts. Academy of Management Review, 25(1), 121-140.

Iyer, A., \& Jetten, J. (2011). What's left behind: identity continuity moderates the effect of nostalgia on well-being and life choices. Journal of Personality and Social Psychology, 101(1), 94-108.

Kumar, N., Stern, L. W., \& Anderson, J. C. (1993). Conducting interorganizational research using key informants. Academy of Management Journal, 36(6), 1633-1651. 
Langley, A. (1999). Strategies for theorizing from process data. Academy of Management Review, 24(4), 691-710.

Langley, A., Golden-Biddle, K., Reay, T., Denis, J.-L., Hébert, Y., Lamothe, L., \& Gervais, J. (2012). Identity struggles in merging organizations renegotiating the sameness-difference dialectic. The Journal of Applied Behavioral Science, 48(2), 135-167.

Lincoln, Y. S., \& Guba, E. G. (1985). TBC. Naturalistic inquiry. Beverly Hills: Sage.

Lupina-Wegener, A. A. (2013). Human resource integration in subsidiary mergers and acquisitions: evidence from Poland. Journal of Organizational Change Management, 26(2), 286-304.

Lupina-Wegener, A., Drzensky, F., Ullrich, J., \& van Dick, R. (2014). Focusing on the bright tomorrow? A longitudinal study of organizational identification and projected continuity in a corporate merger. British Journal of Social Psychology, 53(4), 752-772.

Lupina-Wegener, A. A., Schneider, S. C., \& van Dick, R. (2011). Different experiences of socio-cultural integration: a European merger in Mexico. Journal of Organizational Change Management, 24(1), 65-89.

Marks, M. L., \& Mirvis, P. H. (2001). Making mergers and acquisitions work: strategic and psychological preparation. The Academy of Management Executive, 15(2), 80-92.

Maxwell, J. A., \& Miller, B. A. (2008). Categorizing and connecting strategies in qualitative data analysis. In S. N. Hesse-Biber \& P. Leavy (Eds.), Handbook of emergent methods (pp. 461-478). New York: The Guilford Press.

Meyer, C. B., \& Altenborg, E. (2007). The disintegrating effects of equality: a study of a failed international merger. British Journal of Management, 18(3), 257-271.

Miles, M. B., \& Huberman, M. A. (1994). Qualitative data analysis. Thousand Oakes: Sage.

Mummendey, A., \& Wenzel, M. (1999). Social discrimination and tolerance in intergroup relations: reactions to intergroup difference. Personality and Social Psychology Review, 3, 158-174.

Nahavandi, A., \& Malekzadeh, A. R. (1988). Acculturation in mergers and acquisitions. Academy of Management Review, 13(1), 79-90.

Pettigrew, A. M. (1990). Longitudinal field research on change: theory and practice. Organization Science, 1(3), 267-292.

Pratt, M. G. (2009). From the editors: for the lack of a boilerplate: tips on writing up (and reviewing) qualitative research. Academy of Management Journal, 52(5), 856-862.

Raukko, M. (2009). Organizational commitment during organizational changes: a longitudinal case study on acquired key employees. Baltic Journal of management, 4(3), 331-352.

Riketta, M. (2005). Organizational identification: a meta-analysis. Journal of Vocational Behavior, 66(2), 358-384.

Rousseau, D. (1998). Why workers still identify with organizations. Journal of Organizational Behavior, 19(3), 217-233.

Rouzies, A. (2011). Antecedents of employees' identification with a merger: a three-stage empirical study. International Studies of Management \& Organization, 41(3), 25-41.

Scott, S. G., \& Lane, V. R. (2000). A stakeholder approach to organizational identity. Academy of Management Review, 25(1), 43-62.

Soulsby, A., \& Clark, E. (2011). Theorizing process through punctuated longitudinal case study research. In R. Piekkari \& C. Welch (Eds.), Rethinking the case study in international business and management research (pp. 146-167). Cheltenham: Edward Elgar Publishing Limited.

Stahl, G. K., Larsson, R., Kremershof, I., \& Sitkin, S. B. (2011). Trust dynamics in acquisitions: a case survey. Human Resource Management, 50(5), 575-603.

Tajfel, H., \& Turner, J. C. (1986). The social identity theory of intergroup behaviour. In S. Worchel \& W. G. Austin (Eds.), Psychology of intergroup relations. Chicago: Nelson-Hall.

Terry, D. J., Carey, C. J., \& Callan, V. J. (2001). Employee adjustment to an organizational merger: an intergroup perspective. Personality and Social Psychology Bulletin, 27(3), 267-280.

Terry, D. J., \& O'Brien, A. T. (2001). Status, legitimacy, and ingroup bias in the context of an organizational merger. Group Processes and Intergroup Relations, 4(3), 271-289.

Turner, J. C. (1985). Social categorization and the self-concept: a social cognitive theory of group behavior. Advances in Group Processes: Theory and Research, 2, 77-122.

Turner, J. C., Hogg, M. A., Oakes, P. J., Reicher, S. D., \& Wetherell, M. S. (1987). Rediscovering the social group: a self-categorization theory. Oxford: Basil Blackwell.

Ullrich, J., Wieseke, J., \& van Dick, R. (2005). Continuity and change in mergers and acquisitions: a social identity case study of a german industrial merger. Journal of Management Studies, 42(8), 1549-1569. 
Vaara, E., Tienari, J., \& Säntti, R. (2003). The international match: metaphors as vehicles of social identity building in cross-border mergers. Human Relations, 56(4), 419-451.

van de Ven, A. H. (1992). Suggestions for studying strategy process: a research note. Strategic Management Journal, 13(5), 169-188.

van Dick, R., Ullrich, J., \& Tissington, P. A. (2006). Working under a black cloud: how to sustain organizational identification after a merger. British Journal of Management, 17(Special), 69-79.

van Dijk, R., \& van Dick, R. (2009). Navigating organizational change: change leaders, employee resistance and work-based identities. Journal of Change Management, 9(2), 143-163.

van Knippenberg, D., van Knippenberg, B., Monden, L., \& Lima, F. (2002). Organizational identification after a merger: a social identity perspective. British Journal of Social Psychology, 41(2), 233-252.

van Maanen, J. (1979). The fact of fiction in organizational ethnography. Administrative Science Quarterly, 24(4), 539-550.

Vincze, Z. (2013). In search of generative mechanism: the grounded theory approach to process theory building. In M. E. Hassett \& E. Paavilainen-Mäntymäki (Eds.), Handbook of longitudinal research methods in organisation and business studies (pp. 163-184). Cheltenham: Edward Elgar.

von Krogh, G., Rossi-Lamastra, C., \& Haeliger, S. (2012). Phenomenon-based research in management and organisation science: when is it rigorous and does it matter? Long Range Planning, 45(4), 277-298.

Vora, D., \& Kostova, T. (2007). A model of dual organizational identification in the context of the multinational enterprise. Journal of Organizational Behavior, $28(3), 327$.

Vora, D., Kostova, T., \& Roth, K. (2007). Roles of subsidiary managers in multinational corporations: the effect of dual organizational identification. Management International Review, 47(4), 595-620.

Yin, R. (2009). Case study research: design and methods. Thousand Oakes: Sage. 